\title{
COMPLIANCE CONSUMERISTA: UMA RELAÇÃO DE CREDIBILIDADE ENTRE A ENTIDADE CORPORATIVA E O CONSUMIDOR
}

\author{
Felipe de Poli de Siqueira ${ }^{1}$ \\ Francieli Micheletto ${ }^{2}$
}

\begin{abstract}
RESUMO: O presente trabalho estuda a relação entre o compliance e o direito do consumidor. Nesse sentido, tem-se por objetivo geral analisar o compliance consumerista na perspectiva do ordenamento jurídico específico (Código de Defesa do Consumidor), da ética e da cooperação empresarial, como método de auxiliar na prevenção e combate às ações de corrupção e as benesses trazidas ao consumidor. E, por objetivos específicos, analisar a credibilidade entre a entidade corporativa e o consumidor diante de implantação do compliance. Para tanto, utilizou-se da doutrina a respeito do tema e pesquisa jurisprudencial no âmbito de tribunais brasileiros.
\end{abstract}

PALAVRAS-CHAVE: Compliance; Corrupção; Consumidor; Credibilidade; Ética.

\section{CONSUMERIST COMPLIANCE: A CREDIBILITY RELATIONSHIP BETWEEN THE CORPORATE ENTITY AND THE CONSUMER}

\begin{abstract}
This paper studies the relationship between compliance and consumer law. In this sense, the general objective is to analyze consumer compliance from the perspective of the specific legal system (Code of Consumer Protection), ethics and business cooperation, as a method to assist in preventing and combating corrupt actions and the benefits brought to the consumer. And, for specific objectives, analyze the credibility between the corporate entity and the consumer before implementing compliance. For that, the doctrine was used on the subject and jurisprudential research in the scope of Brazilian courts.
\end{abstract}

KEYWORDS: Compliance; Corruption; Consumer; Credibility; Ethic.

\footnotetext{
${ }^{1}$ Doutorando em Direito Econômico e Socioambiental pelo Programa de Pós Graduação da Pontifícia Universidade Católica do Paraná. Bolsista pelo CAPES. Mestre em Direito Econômico e Socioambiental pelo Programa de Pós Graduação da Pontifícia Universidade Católica do Paraná. Linha de Pesquisa: Estado, atividade econômica e desenvolvimento. Especialista em Direito Civil e Empresarial e em Direito e Processo Tributário Empresarial pela Pontifícia Universidade Católica do Paraná. Advogado. E-mail: felipe @ psem.adv.br.

2 Especialista em Direito Civil e Processo Civil pelo Centro Universitário Curitiba - PR - Brasil (UNICURITIBA). Bacharel em Direito pelo Centro Universitário Curitiba. Advogada.
} 


\section{INTRODUÇÃO}

O termo compliance tem sido palavra corriqueira utilizada na mídia e grandes entidades corporativas nos últimos tempos, principalmente, diante dos acontecimentos ligados a operação "lava jato" e a edição da Lei n. 12.846/2013 - Lei Anticorrupção, que discute sobre a responsabilidade das pessoas jurídicas por danos à administração pública. Desde então, o compliance é um instituto utilizado com o intuito de combate à corrupção. Entretanto, não é apenas o combate à corrupção que trata o referido instituto, como será demonstrado no presente artigo.

Não obstante o aumento da atuação dos órgãos de contenção à corrupção tenha impulsionado o desenvolvimento do presente tema, o compliance não se limita apenas a esta área, podendo alcançar diversas outras áreas do Direito, como Direito Concorrencial, Ambiental, Penal, Trabalhista, Tributário e também o Direito do Consumidor. Embora poucos sejam os estudos empenhados no tema, a proteção dos interesses do consumidor é um campo pleno de probabilidades de aplicação do instituto do compliance, sendo que por vezes o programa é implantado com interesses econômicos à empresa gerando efeitos secundários de benefícios ao consumidor.

O conceito de compliance está intimamente ligado a um instrumento de governança, administração e boas práticas das empresas. Ocorre que, quando estendido as relações consumeristas, alcança também um viés além de empresarial e social.

O compliance consumerista ou consumer compliance não está apenas ligado à capacidade da empresa em minimizar os riscos referentes às ações judiciais ou multas administrativas e, por conseqüência, as futuras dívidas que possam advir destas, o seu escopo é também a fidelização do público alvo por meio da edificação de uma relação de credibilidade entre a empresa e o consumidor.

A questão em comento se tornará tão interessante ao Poder Judiciário como para as partes da relação de consumo, pois, além de diminuir as demandas consumeristas que inflam diariamente o Poder Judiciário, também trará o equilíbrio ideal na relação entre consumidor, empresa e órgão público. 


\section{COMPLIANCE CONSUMERISTA: UMA RELAÇÃO DE CREDIBILIDADE ENTRE A ENTIDADE CORPORATIVA E O CONSUMIDOR}

Então, o presente artigo traz seu posicionamento acerca da utilização do instituto do compliance na esfera consumerista sob a óptica do consumidor e as benesses que tal implementação poderá trazer ao triângulo consumidor, empresa e órgão público.

Neste cenário, se pretende enfrentar o seguinte problema: os programas de compliance, desde que adaptados ao direito pátrio, estão em condições de servir para equacionar o exercício do direito à informação e à proteção do consumidor com uma postura empresarial focada no gerenciamento dos riscos que poderão emergir dos contratos consumeristas?

Nesta toada, a presente pesquisa mostra-se imprescindível no que concerne aos novos posicionamentos e mecanismos empresariais de maximização de lucros, minimização de riscos, confiabilidade entre consumidor e empresa contratada.

Primeiramente, será apresentado no tópico 2 uma breve síntese do instituto do compliance e suas definições, objetivos e formas de implantação.

Enfrentado o tema, o presente estudo irá enveredar para o conceito, evolução e atualização do contrato com base no Código de Defesa do Consumidor - CDC, verificando em suma as novas tendências contratuais no que concerne aos contratos de consumo, e, diante de tais tendências, como se daria a aplicação do compliance nas empresas e como seria estendido ao consumidor.

No tópico 4 serão analisados o instituto do compliance no Direito do Consumidor, bem como a importância da ética, cooperação e confiança na economia e na relação consumerista.

No tocante ao tema, embora o mesmo trate de questões atuais e ainda pouco discutidas, o objetivo do presente artigo não é a simples conceituação de institutos jurídicos e econômicos, mas sim dispor acerca da atual visão da aplicação e implantação do compliance nas corporações e os reflexos trazidos para a empresa e por extensão aos consumidores. Para tanto, utilizou-se da doutrina a respeito do tema e pesquisa jurisprudencial no âmbito de tribunais brasileiros.

E, por fim, são apresentadas as considerações finais do presente trabalho, demonstrando a real necessidade de estudo do tema e arrematando as discussões travadas neste artigo. 


\section{DO INSTITUTO DO COMPLIANCE SOB A ÓPTICA EMPRESARIAL: DEFINIÇÕES, OBJETIVOS E FORMAS DE IMPLANTAÇÃO}

Para a análise do tema abordado neste artigo é necessário fazer uma breve referência do instituto do compliance e suas definições, objetivos e formas de implantação.

O agravamento das leis e a forte pressão internacional, com intenção de estimular a participação do setor privado no gerenciamento adequado de variáveis, deram propulsam para uma nova tendência de minimização dos riscos da sociedade, o que é chamado de instituto do compliance. $\mathrm{O}$ instituto funciona com escopo de controle, proteção e prevenção de práticas criminosas nas corporações, evitando ou amenizando a responsabilidade quando do aparecimento de alguma patologia corruptiva (CASTELLA; GABARDO, 2015, p. 134).

O compliance se trata de um procedimento que se volta para a concretização da missão, da visão e dos valores de uma empresa, não sendo definido apenas como um instituto de simples cumprimento de regras formais, mas uns instituo de alcance muito mais amplo.

O instituto "é um conjunto de regras, padrões, procedimentos éticos e legais, que, uma vez definido e implantado, será a linha mestra que orientará o comportamento da instituição no mercado em que atua, bem como a atitude dos seus funcionários" (CANDELORO et al., 2012, p. 30).

Será, portanto, um instituto responsável pelo controle dos riscos regulatórios e de reputação, diga-se aqui, com fonte nas leis, convenções do mercado, códigos e padrões estabelecidos por associações, órgãos regulatórios e códigos de conduta (COIMBRA; MANZI, 2010, p. 2). Sendo tal cargo realizado por um compliance officer, o qual será independente e terá acesso ao Conselho de Administração.

Identificam-se três ordens de efeitos jurídicos atribuídos ao compliance: (i) circunstância atenuante das sanções administrativas; (ii) critério para aferição da culpa nas ações de responsabilidade dos dirigentes ou administradores das empresas; e (iii) obrigação legal para contratantes com poder público, empresas públicas e sociedades de economia mista.

Nota-se o reconhecimento destes efeitos em ação judicial ajuizada contra a Petrobras por empresa excluída de processo licitatório, o Tribunal de Justiça do Rio de Janeiro - TJRJ concluiu que “a exclusão está fundada em elementos objetivos de compliance, especificamente pelo fato de o grupo empresarial da Autora estar diretamente envolvido nas 


\section{COMPLIANCE CONSUMERISTA: UMA RELAÇÃO DE CREDIBILIDADE ENTRE A ENTIDADE CORPORATIVA E 0 CONSUMIDOR}

investigações da Operação Lava Jato, cujas irregularidades implicaram em ser considerada como elevado grau de risco"3.

Os tribunais têm gradativamente considerado a existência de um programa sério de compliance como parâmetro interpretativo para a resolução de questões.

A $4^{\mathrm{a}}$ turma do Superior Tribunal de Justiça - STJ utilizou-se do compliance como fundamento para justificar a impossibilidade da apólice de um seguro de responsabilidade civil de diretores e administradores cobrir a prática de atos dolosos nos seguintes termos, como se denota de parte do voto do relator: "A apólice do seguro de RC D\&O não pode cobrir atos dolosos, principalmente se cometidos para favorecer a própria pessoa do administrador, o que evita forte redução do grau de diligência do gestor ou a assunção de riscos excessivos, a comprometer tanto a atividade de compliance da empresa quanto as boas práticas de governança corporativa. Aplicação dos arts. 757 e 762 do CC"4.

Ainda, a mesma turma do STJ, em ação movida por companhia com vistas à imposição de responsabilidade civil ao seu ex-diretor por alegada gestão temerária e exorbitância de suas funções, entendeu que uma das razões ensejadoras da condenação era que "como administrador principal da companhia tinha por obrigação implementar e fomentar boas práticas de governança corporativa, utilizando-se, para isso, de parâmetros/instrumentos legais e morais com vistas a aumentar o valor da sociedade, facilitar seu acesso ao capital e contribuir para a sua perenidade" $"$.

Ao mais, o Tribunal de Justiça do Estado de São Paulo - TJSP entendeu que o não cumprimento das normas de compliance seria embasamento para resilição unilateral do contrato consumerista de conta corrente por parte da instituição bancária, o que o fez nos seguintes termos: "É certo que contratos de conta corrente, por serem destinados à longa duração, geram na parte a justa expectativa de continuidade. Desse modo, mostrar-se-ia ilícita a resilição de avenças dessa natureza de forma imotivada, pelo ferimento frontal à boa-fé objetiva, que deve ser respeitada de forma cogente, nos termos do artigo 422 do Código Civil. Ocorre, entretanto, que, no caso em tela, a conduta do réu foi lícita, na medida em que a rescisão do contrato teve por justificativa o não atendimento às regras de compliance por parte da autora. (...). Com efeito, nestes autos pôde-se concluir que o encerramento da conta foi

\footnotetext{
${ }^{3}$ TJRJ, AI 0036371-65.2017.8.19.0000. Relator: Desembargadora Maria Regia Fonseca Nova Alves, julgado em 27/03/2018, reg. em 02/05/2018.

${ }^{4}$ STJ, RESP 1.601.555/SP. Relator: Ministro Ricardo Villas Bôas Cueva, julgado em 14/02/2017, reg. em 20/02/2017.

${ }^{5}$ STJ, RESP 1.475.706/SP. Relator: Ministro Marco Buzzi, julgado em 06/11/2014, reg. em 27/02/2015.
} 
ocasionado por violação às regras de compliance pela autora. Afinal, programas de integridade em empresas dependem do envolvimento e da colaboração de sua alta administração para serem efetivos, o que, evidentemente, não ocorreu no âmbito da empresa autora"

Pois bem, analisando as jurisprudências pátrias tem-se que o compliance é matéria vastamente ventilada e discutida nos tribunais brasileiros, no intuito de evitar o elevado grau de risco.

Assim, a conceituação de compliance, seus objetivos e forma de implantação podem ser retirados de documentos e regras feitos por diversos órgãos internacionais, que se voltam à determinado ramo de atividade (DINIZ; RIBEIRO, 2015, p. 89)

Os objetivos da implementação do compliance são os mais variados, mas se citam alguns: cumprir com a legislação nacional e internacional, regulações do mercado e normas internas da corporação; precaver-se de futuras demandas judiciais; transparência na condução dos negócios; salvaguardar a confidencia da informação dada por clientes; evitar o conflito de interesse; evitar ganhos pessoais indevidos através da manipulação e uso da informação privilegiada; evitar a lavagem de dinheiro; e, por fim, disseminar na cultura organizacional, por meio de treinamento e educação, os valores de compliance (CANDELORO et al., 2012, p. 37-38).

Portanto, para implementar um programa de compliance "a empresa deverá inicialmente elaborar um programa com base na sua realidade, cultura, atividade, campo de atuação e local de operação" (DINIZ; RIBEIRO, 2015, p. 89).

Assim, diante da implantação do referido programa de forma efetiva, a empresa tende a obter mais confiança e maior credibilidade no mercado, alcançando elevados níveis de cooperação interna e externa, com aumento de lucro, mas sempre de forma sustentável, trazendo melhoramentos à corporação, a seus empregados e à sociedade em geral (DINIZ; RIBEIRO, 2015, p. 90)

Neste ínterim, cumpre trazer as lições de DINIZ e RIBEIRO (2015, p. 90) quando asseveram que:

Com a implantação da política de Compliance, a empresa tende a: orientar todas as suas ações para os objetivos definidos; utilizar os recursos de forma mais eficiente, visto que as decisões passam a ser mais econômicas, pois uniformes para casos

${ }^{6}$ TJSP, AP 1013073-57.2016.8.26.0100. Relator: Desembargador Sergio Rui, julgado em 16/11/2017, reg. em $17 / 11 / 2017$. 
similares; "proteção contra as pressões das emergências"; ter uniformidade e coerência em todos os seus atos e decisões, colaborando com a transparência dos processos; facilitar a adaptação de novos empregados à cultura organizacional; disponibilizar aos gestores mais tempo para repensar políticas e atuar em questões estratégicas; aumentar e aperfeiçoar o conhecimento da organização por todos os seus atores.

Assim, percebe-se que o programa de compliance, além de trazer benefícios ao próprio desenvolvimento empresarial, trará reflexos benéficos aos consumidores da corporação.

Destacam-se no presente artigo os benefícios de tal implantação na sociedade, pois o compliance não se limita apenas às questões empresariais, podendo alcançar diversas outras áreas do direito, dentre elas o Direito do Consumidor. Mesmo o tema sendo pouco estudado, a proteção dos interesses do consumidor é um campo vasto de probabilidades de aplicação de tal política, com vistas à redução do número de lesões causadas aos direitos consumeristas e à efetiva implementação das normas do CDC (OLIVEIRA, 2017, p. 53).

Analisando o cenário atual tanto no campo do direito quanto da economia "nunca se exigiu tanto das organizações uma conduta íntegra e responsável como nos tempos atuais, [...]", sendo que tal modificação se deu com base na "maior circulação de informação e provocou um aumento da transparência das organizações e, conseqüentemente, das expectativas da sociedade em geral em relação ao seu comprometimento ético" (COIMBRA; MANZI, 2010, p. 11). Assim, diante de tal perspectiva existe um regresso a determinados valores da cultura humana que pareciam estar perdidos.

\section{CONCEITO, EVOLUÇÃo E ATUALizaÇão do CONTRATO DE CONSUMO COM BASE NO CDC}

A atual concepção de contratos é uma concepção social, "para a qual não só o momento da manifestação da vontade (consenso) importa, mas onde também e principalmente os efeitos do contrato na sociedade serão levados em conta e onde a condição social e econômica das pessoas nele envolvidas ganha em importância” (MARQUES, 2014, p. 213).

No intuito de encontrar um equilíbrio contratual na sociedade de consumo, o direito se utilizará da lei (no caso, o CDC) como limitador e legitimador da autonomia da vontade, que protegerá os interesses sociais, valorizando a confiança depositada no vínculo, as expectativas e a boa-fé das partes contratantes (MARQUES, 2014, p. 214). 
Importante, neste aspecto, frisar os princípios basilares dos contratos de consumo: princípio da conservação; princípio da boa-fé; princípio da equivalência; princípio da igualdade; princípio da transparência e dever de informação.

Desta forma, o direito desenvolve uma teoria contratual com função social, com leis mais concretas, menos conceituais e mais funcionais, que para alcançar a solução dos novos problemas opta por soluções mais abertas, deixando margem de ação ao magistrado para chegar a uma solução justa ao caso concreto (MARQUES, 2014, p. 217-218).

Assim, diante da disparidade nos contratos consumeristas o direito criou mecanismos para uma proteção mais efetiva ao consumidor, que por muitas vezes ficava a mercê de políticas não muito corretas das empresas prestadoras de serviço.

Todavia, após vários anos de vigência do CDC, embora tenham sido vistos alguns progressos, tanto em econômicos como jurídicos, a relação de consumo ainda é ditada por inúmeros litígios judiciais. Sendo que por muitas vezes o Poder Judiciário se torna obsoleto e moroso para resolução de tais conflitos, não alcançando o fim desejado. Ora, tornou-se urgente à procura por outras formas de salvaguardar os direitos do consumidor.

Consequentemente, no que concerne à evolução dos conceitos de direito civil, tornase importante o estudo do compliance consumerista, o qual, conforme explanação a seguir, não está apenas ligado à capacidade da empresa em minimizar os riscos referentes às ações judiciais ou multas administrativas, mas também com o escopo de fidelização do público alvo por meio da edificação de uma relação de credibilidade entre a empresa e o consumidor. $\mathrm{Ou}$ seja, o Direito do Consumidor e os próprios tribunais teriam mais um aliado na proteção dos direitos dos consumidores, qual seja, a implantação de políticas de compliance nas empresas, que trariam transparência na condução dos negócios, bem como confiabilidade ao contratante e, portanto, uma diminuição da procura ao Poder Judiciário, evitando e diminuindo a enxurrada de demandas consumeristas.

Neste contexto, o programa intitulado "Collective Actions", promove a utilização de "pactos de integridade", que são instrumentos de precaução à corrupção em contratações públicas, onde as empresas de determinados setores voluntariamente se empenham a adotar práticas éticas e transparentes, segundo regras convencionadas. São exemplos o Instituto Ética Saúde e o Pacto pelo Esporte, os quais, sendo práticas de compliance coletivo e embora admitam como escopo primordial a eliminação de condutas de corrupção, também trazem à 


\section{COMPLIANCE CONSUMERISTA: UMA RELAÇÃO DE CREDIBILIDADE ENTRE A ENTIDADE CORPORATIVA E O CONSUMIDOR}

baila a proteção de consumidores e podem ser utilizados por outros setores, com base nestes interesses (CARPENA, 2018, p. 01).

\section{COMPLIANCE CONSUMERISTA}

A intenção do compliance consumerista não está apenas ligada à redução de riscos referentes às ações judiciais ou multas, mas também na fidelização do contratante através da construção de uma relação de credibilidade entre as partes. Decorre de uma nova incorporação cultural de toda cadeia hierárquica empresarial que tem por objetivo irradiar seus valores por toda a pirâmide basilar constituinte do capital humano ali pertencente (AZEVEDO; COELHO, 2017, p. 01).

Deste modo, para a devida implantação da política de compliance, a empresa deve realizar um programa baseado em sua realidade, cultura, atividade, atuação e local de trabalho, sendo implantando em todas as entidades ligadas a empresa, precipuamente estabelecendo políticas através de um Código de Ética, criação de comitê, treinamentos, irradiação da cultura do compliance, monitoramente do risco, revisões, estímulos e criação de um canal para recebimento de denúncias/reclamações, com posterior averiguação e aplicação de sanções (DINIZ; RIBEIRO, 2015, p. 89-90).

Neste diapasão, torna-se urgente o treinamento e a comunicação para realizar esta mudança de padrão empresarial que contará com ajuda de outras áreas conexas atuando diretamente na proteção ao consumidor.

A análise do Poder Judiciário serve como instrumento de auditoria, ao demonstrar tendências resultantes de um mapeamento que emerge no plano do compliance consumerista. Assim, distribuem-se as análises de riscos operacional, legal e da imagem, onde se concentra o enfoque para gestão jurídica das corporações na atualidade. A presente atuação passou a ser forçosa dentro do mundo corporativo, pois, de um Poder Judiciário que se conflagra periodicamente em progressão continuada, a gestão em si não trará o equilíbrio ideal na relação entre consumidor, empresa e órgão público, sendo necessário mudar os padrões de atuação pretéritos (AZEVEDO, COELHO, 2017, p. 01).

Relevante, portanto torna-se a análise do Poder Judiciário para que haja uma implementação completa do programa de compliance. 
Também, relevante traçar um paralelo entre a Justiça norte-americana e a brasileira. Enquanto que na norte-americana as indenizações têm intuição de punir, no Brasil se trata de um caráter ressarcitório, com o viés punitivo voltado para o âmbito educativo. Embora não se tenha no Brasil indenizações vultuosas, a facilidade com que o consumidor tem de prestar sua reclamação à empresa, na esfera judicial ou administrativa, gerou inúmeras ações, e estas somadas fazem os valores gastos com indenização serem de grande vulto. Assim, os programas de compliance voltados para o consumidor tornam-se soluções no presente caso, havendo a devida reestruturação da cadeia de produção e do ao consumidor. Assim, tem-se que o Poder Judiciário atuando em caráter educativo enseja a fixação estratégica consumerista ao instituto do compliance dentro das empresas, algo que já aconteceu, de modo distinto, nos Estados Unidos (AZEVEDO, COELHO, 2017, p. 01).

Importante citar as lições de AYRES et al. (2013, p. 169), os quais aduzem acerca da importância dada pelas conseqüências trazidas pelo descumprimento de programas anticorrupção:

\begin{abstract}
De fato, as consequiências trazidas a pessoas físicas e jurídicas pelo descumprimento anticorrupção têm sido cada vez mais significativas. Além da aplicação de multas milionárias, em especial nos Estados Unidos, notícias envolvendo prática de corrupção causam sérios danos à reputação das empresas. A simples comunicação ao mercado de que uma empresa está em processo de investigação ou colaborando com as autoridades na apuração de possíveis violações de legislações anticorrupção gera efeitos imediatos no valor das ações da empresa.
\end{abstract}

Por certo que no Brasil também se inicia um anseio da sociedade pelo combate à corrupção, sendo intoleráveis pela sociedade os desvios de conduta. Se em um passado remoto trata-se apenas de corrupção no meio público, atualmente, a sociedade, enquanto consumidora, questiona o papel desempenhado pelas empresas no que concerne as práticas de corrupção, cobrando a devida responsabilização (AYRES et al., 2013, p. 170).

O comportamento empresarial correto demonstra ao mercado segurança, previsibilidade, confiança e boa reputação, facilitando as negociações e fazendo isto um círculo vicioso (FORGIONI, 2003, p. 12-29).

Ainda neste sentido, cumpre citar a economista política FUKUYAMA (1995, p.11) que defende que as relações negociais devem ser fomentadas pela reciprocidade:

Law, contract, and economic rationality provide a necessary but not sufficient basis for both the stability and prosperity of postindustrial societies; they must as well be 


\section{COMPLIANCE CONSUMERISTA: UMA RELAÇÃO DE CREDIBILIDADE ENTRE A ENTIDADE CORPORATIVA E O CONSUMIDOR}

leavened with reciprocity, moral obligation, duty toward community, and trust, which are based in habit rather than rational calculation. ${ }^{7}$

Nesta toada, o projeto de lei sob n. 6826/2010 visava atender compromissos de combate à corrupção assumidos pelo Brasil, em especial, os dispositivos previstos na Convenção da Organização para Cooperação e Desenvolvimento Econômico, esta intenção manteve-se e o projeto de lei foi aprovado, tornou-se lei ordinária - Lei n. 12.846/2013, que dispõe sobre a responsabilidade administrativa e civil das pessoas jurídicas -, vigorando o que se denominou de Lei Anticorrupção. Fato é que diante disto muitas empresas brasileiras encontram-se sujeitas as rígidas legislações que tem alcance extraterritorial.

A implantação do instituto do compliance torna-se essencial, seja para inibir quaisquer condutas de corrupção evitando multas, seja para alcançar benefícios ao próprio desenvolvimento empresarial, estes alcançarão reflexos benéficos aos consumidores da empresa em questão.

Neste sentido, além da utilização do compliance nas empresas imprimir à sociedade e aos consumidores condutas desejáveis, o tratamento diferenciado para tais empresas faz "minimizar desvantagens competitivas e reduzir distorções de mercado que beneficiariam aquelas que nada fazem para evitar práticas ilícitas” (AYRES et al., 2013, p. 171).

Assim, a empresa que se utiliza de tais programas além de trazer consequiências positivas para seus consumidores diretamente, também ajuda a "retirar" do mercado empresas que não se adéquem a tais propósitos, fazendo com que haja uma relação de credibilidade e confiabilidade entre consumidor e empresa.

Fica evidente que as corporações não devem somente investir em novas tecnologias, mas também, e principalmente, no potencial criador de direcionamento de comportamentos, sendo primordial uma atuação bem conectada entre o negócio e o jurídico, por meio de trabalhos institucionais que possam precaver-se de ações judiciais e administrativas, com base em dados do Poder Judiciário e dos órgãos de proteção ao consumidor. Tal procedimento trará mútua fidelização das partes, a qual passa a ser a finalidade precípua das empresas que dominarão o mercado da nova era digital (AZEVEDO; COELHO, 2017, p. 01).

\footnotetext{
7 Tradução livre: "Lei, contrato e racionalidade econômica fornecem uma base necessária, mas não suficiente, tanto para a estabilidade quanto para a prosperidade das sociedades pós-industriais; essas devem também ser fermentadas com a reciprocidade, a obrigação moral, o dever para com a comunidade, e a confiança, que são baseados no hábito em vez do cálculo racional".
} 


\title{
4.1. Da Importância da Ética nas Relações Econômicas e de Consumo
}

A introdução do estudo da ética na economia é trazida por Amartya Sen, que em poucas palavras, defende um desenvolvimento promovido pela ética na economia, devendo ser verificada a condição de bem-estar e a condição de agente. Por bem-estar entende-se a aplicação da justiça distributiva e por condição de agente entende-se a utilização de uma visão mais ampla da pessoa, abarcando a valorização dos elementos aspirados pelo agente (SEN, 1999, p. 94-106)

Pois bem, diante do cenário atual conforme vastamente demonstrado acima, é requisito que as corporações empresariais ajam de forma sustentável e assim se insiram na sociedade através da ética negocial, a qual trará resultados benéficos a seus consumidores, dentre eles equilíbrio, transparência e credibilidade.

Sobre o tema, cabe destacar o que DINIZ e RIBEIRO (2015, p. 91) asseveram:

\begin{abstract}
Pela junção entre economia (mercado), direito e ética, surge a transparência, requisito essencial para o Compliance e, por consequência, para o bom funcionamento do mercado, visto que gera confiança e cooperação, pois os atores podem prever a jogada dos demais. Dentro de tal contexto, tem-se como exemplo dessa interação a Lei Sarbanes-Oxley (SOX), cujo objetivo é conferir maior transparência e confiabilidade aos resultados das empresas, aumentando, por exemplo, o grau de responsabilidade, "desde o presidente e a diretoria da empresa, até as auditorias e advogados contratados" (CANDELORO; RIZZO, 2012, p. 296297), e funcionando como um incentivo ideal para o intercâmbio entre direito, economia e mercado, em prol do bem comum.
\end{abstract}

A aplicação de programas de compliance torna o direito e as relações negociais mais próximas a ética, a qual trará resultados positivos a sociedade consumidora.

A criação de uma consciência ética, que traga aversão aos empresários que utilizam da corrupção e outras ações que não se enquadram nos padrões de condutas mínimos aceitáveis, para obtenção de vantagens deverá gerar resultados negativos, afastando o consumidor consciente e informado. Então, utilizar valores éticos significa para a empresa agir com espontaneidade, seguindo regras de conduta. Igualmente, as empresas devem prezar pela responsabilidade legal aos seus consumidores, a qual estará englobada no programa de compliance (QUIRINO, 2017, p. 01).

Esta implantação de política de boas práticas constituída através de um programa sério de compliance especializado reduz riscos legais do negócio e traz maior confiabilidade 


\section{COMPLIANCE CONSUMERISTA: UMA RELAÇÃO DE CREDIBILIDADE ENTRE A ENTIDADE CORPORATIVA E O CONSUMIDOR}

aos consumidores, que conforme citado acima, é ponto importante na escolha na do consumidor ao escolher a empresa com a qual irá contratar.

\subsection{Da Cooperação e da Confiança}

A cooperação e a confiança são essenciais para o desenvolvimento da empresa e, por conseguinte, da relação consumerista entre empresa e consumidor.

A cooperação na empresa, internamente, faz com que os funcionários estejam mais satisfeitos e com isto aumentam sua produtividade e externamente, faz com que hajam relações mais estáveis, tornando-as mais seguras e com credibilidade para todas as partes na negociação (DINIZ; RIBEIRO, 2015, p. 95).

Assim, para que haja a referida cooperação é necessário "aumentar a importância do futuro em relação ao presente; alterar as recompensas dos jogadores a partir dos quatro resultados possíveis numa jogada; e ensinar aos jogadores valores, por exemplos, e práticas que irão promover a cooperação" (AXELROD, 2010, p. 118).

Portanto, para AXELROD (2010, p. 121-132) haverá cooperação quando houver importância ao futuro, tornando necessário o incentivo a tal conduta. Isto fará com que as pessoas se importem umas com as outras, trazendo reciprocidade e reconhecimento.

No caso específico do compliance, a finalidade é também realizar ações empresariais em conformidade com o que dispõe o CDC. Conforme analisado acima, a implantação da política de compliance na corporação, além de minimizar os riscos de multas e ações judiciais e danos pecuniários, também faz com que haja uma relação de credibilidade entre empresa e consumidor.

Conclui-se que cabe ao empresário a proteção de seus clientes, sem que deste queira retirar vantagens indevidas. Para DINIZ e RIBEIRO (2015, p. 95) “cabe aos demais empresários atuar com ética e transparência nos negócios; e cabe ao consumidor adquirir produtos e serviços das empresas sustentáveis, a fim de priorizar o verdadeiro desenvolvimento".

O desenvolvimento empresarial através da aplicação de programas de compliance faz com que hajam benesses a empresa que serão transferidas ao consumidor, que se fidelizará a determinada marca sustentável, fazendo uma cadeia a qual terá empresas sustentáveis e éticas 
trabalhando em pleno desenvolvimento, diminuição de demandas judiciais e aumento de satisfação e credibilidade ao consumidor.

Para COIMBRA e MANZI (2010, p. 5) a credibilidade pública que uma empresa apresenta trará sucesso as organizações:

O sucesso das organizações é extremamente dependente da admiração e da confiança pública, refletida no valor de suas marcas, na sua reputação, na capacidade de atrair e fidelizar clientes, investidores, parceiros e até os empregados. Estudos recentes têm demonstrado como estão à frente as organizações que apresentam uma estrutura sólida de preceitos éticos e atuam de forma responsável, em detrimento das demais que atuam de forma diversa.

Por isto, as práticas compliance, para surtirem efeitos positivos, devem ser incorporadas por toda cadeia hierárquica da empresa, sua implantação é uma ferramenta importante para alcançar um ambiente transparente, ético e de confiança que resguarde os direitos consumeristas e, portanto, tenha em seus clientes uma relação de credibilidade entre a entidade corporativa e o consumidor.

\section{CONSIDERAÇÕES FINAIS}

O presente trabalho procurou analisar a regulamentação da implantação dos programas de compliance de acordo com a legislação atual dentro das empresas no intuito de verificar os efeitos trazidos ao direito do consumidor e por excelência ao próprio consumidor.

A atual fase do direito e do nosso país reclama por políticas empresariais mais éticas e que inspirem confiança e credibilidade ao seu consumidor, pois é inimaginável que uma empresa atue no mercado negocial atual sem a utilização dos princípios de governança corporativa e de uma política de compliance, principalmente após o fortalecimento de uma parcela de consumidores decisivos, que adquirem condutas e valores éticos, e não mais somente produtos ou serviços.

Desta forma, o referido artigo tratou da compliance consumerista a qual mesmo que em efeito secundário trará uma relação de credibilidade entre empresa e consumidor.

O compliance consumerista ou consumer compliance não está apenas ligado à capacidade da empresa em minimizar os riscos referentes às ações judiciais ou multas administrativas é também a capacidade de fidelização do público alvo por meio da edificação de uma relação de credibilidade entre a empresa e o consumidor. 


\section{COMPLIANCE CONSUMERISTA: UMA RELAÇÃO DE CREDIBILIDADE ENTRE A ENTIDADE CORPORATIVA E O CONSUMIDOR}

Os próprios tribunais pátrios têm utilizado o cumprimento previsto no compliance para fundamentar seus julgamentos, baseados na ética, cooperação, transparência e confiabilidade.

Evidente que as empresas não devem somente investir em novas tecnologias, mas também, em políticas de compliance trazendo mútua fidelização das partes, a qual passa a ser a finalidade precípua das empresas que dominarão o mercado da nova era digital.

A implantação da política de compliance tende a gerar vantagem competitiva, sendo que os consumidores altamente críticos requerem uma posição ética e sustentável da empresa, além de seus efeitos em termos de confiança pública.

Assim, a ampliação da corporação através da aplicação de programas de compliance faz com que haja benefícios a empresa que serão transferidos diretamente ao consumidor, que será fiel a determinada marca sustentável, sendo que tais ações farão um círculo vicioso o qual farão parte empresas sustentáveis e éticas trabalhando em pleno desenvolvimento econômico, diminuição de demandas judiciais e administrativos e por fim aumento de satisfação e credibilidade ao consumidor.

O consumidor será respeitado, ouvido através de canais ligados diretamente a empresa, (atendimento, comércio eletrônico, mídia informacional, plataforma e-consumidor, Serviço de Atendimento ao Consumidor - SAC e ouvidoria, recall e resolução amigável de possíveis conflitos), e por conseqüência será menos lesado.

Considera-se, portanto, que as questões em comento, com a mudança dos paradigmas atuais, ainda não têm posições sólidas e concretas. Ainda assim, é importante que se identifique no caso concreto as garantias consumeristas que poderão ser resguardadas com a aplicação de um programa de compliance nas empresas, percebendo sempre a necessidade de mudança da cultura em nosso país.

Entende-se, portanto, que somente em havendo uma maior discussão sobre a regulamentação dos programas compliance e da lei anticorrupção empresarial, bem como sua aplicação prática, tornar-se-á mais segura e concreta a orientação das condutas e comportamentos das pessoas interessadas na aplicação do instituto, bem como seus desdobramentos futuros. 


\section{REFERÊNCIAS BIBLIOGRÁFICAS}

AYRES, Carlos Henrique da Silva; DEBBIO, Alessandra Del; MAEDA, Bruno Carneiro. Temas de Anticorrupção e Compliance. Rio de Janeiro: Elsiver, 2013.

AXELROD, Robert. A evolução da cooperação. Tradução de Jusella Santos. São Paulo: Leopardo Editora, 2010.

AZEVEDO, Leonardo Neri Candido de Azevedo; COELHO, Pedro Franco. A realidade do compliance para consumidores. 2017. Disponível em: <https://politica.estadao.com.br/blogs/fausto-macedo/a-realidade-de-compliance-paraconsumidores $>$. Acesso em: 04 setembro 2018.

BRASIL. Superior Tribunal de Justiça. Recurso Especial $\mathrm{n}^{\circ}$ 1.475.706/SP. Recorrente: Espólio de Alvaro de Souza Barro.Recorrido: Corretora Souza Barros Câmbio e Títulos S/A. Relator: Ministro Marco Buzzi. Brasília, julgado em 06/11/2014, reg. em 27/02/2015.

Superior Tribunal de Justiça. Recurso Especial $\mathrm{n}^{\circ}$ 1.601.555/SP. Recorrente: Antonio Jose Monteiro da Fonseca de Queiroz. Recorrido:ACE Seguradora S/A. Relator: Ministro Ricardo Villas Bôas Cueva. Brasília, julgado em 14/02/2017, reg. em 20/02/2017.

- Tribunal de Justiça do Rio de Janeiro. Agravo de Instrumento n ${ }^{\circ}$ 003637165.2017.8.19.0000. Agravante: Petróleo Brasileiro S/A - Petrobras. Agravado: Monitore Segurança Patrimonial. Relator: Desembargadora Maria Regia Fonseca Nova Alves. Rio de Janeiro, julgado em 27/03/2018, reg. em 02/05/2018.

Tribunal de Justiça de São Paulo. Apelação Cível no 1013073-57.2016.8.26.0100. Apelante: Viscaya Holding Participações, Intermediações, Cobranças e Serviços Ltda. Apelado: Banco Bradesco S/A. Relator: Desembargador Sergio Rui. São Paulo, julgado em 16/11/2017, reg. em 17/11/2017.

Lei ordinária n. 12.846, de $1^{\circ}$ de agosto de 2013. Dispõe sobre a responsabilização administrativa e civil de pessoas jurídicas pela prática de atos contra a administração pública, nacional ou estrangeira, e dá outras providências. Diário Oficial da União, Brasília, 2 ago. 2013. Disponível em: <http://www.planalto.gov.br/ccivil_03/_ato20112014/2013/lei/112846.htm>. Acesso em: 03 agosto 2018.

CANDELORO, Ana Paula; RIZZO, Maria Balbina Martins de; PINHO, Vinícius. Compliance $360^{\circ}$ : riscos, estratégias, conflitos e vaidades no mundo corporativo. São Paulo: Trevisan Editora Universitária, 2012. 
CARPENA, Heloisa. O compliance consumerista e criação de um mercado ético e produtivo. Disponível em: <https://www.conjur.com.br/2018-ago-01/garantias-consumocompliance-consumerista-criacao-mercado-etico-produtivo>. Acesso em: 04 setembro 2018.

CASTELlA, Gabriel Morretini e; GABARDO, Emerson. A nova lei anticorrupção e a importância do compliance para as empresas que se relacionam com a Administração Pública. Revista de direito administrativo e constitucional. ano 15, n. 60, p. 129-147, abr/jun. 2015.

COIMBRA, Marcelo de Aguiar; MANZI, Vanessa Alessi (Coord.). Manual de Compliance: preservando a boa governança e a integridade das organizações. São Paulo: Atlas, 2010.

DINIZ, Patrícia Dittrich Ferreira; RIBEIRO, Marcia Carla Pereira. Compliance e Lei Anticorrupção nas Empresas. Revista de Informação Legislativa. ano 52, n. 205, p.87-105, mar. 2015.

FORGIONI, Paula A. A interpretação dos negócios empresariais no novo código civil brasileiro. Revista de direito mercantil, Nova série. ano 42, n. 130, p. 7-38, abr./jun. 2003.

FUKUYAMA, Francis. Trust: The Social Virtues and the Creation of Prosperity. New York: Fress Press, 1995.

MARQUES, Claudia Lima. Contratos no Código de Defesa do Consumidor - O novo regime das relações contratuais. 7. ed. São Paulo: Revista dos Tribunais, 2014.

OLIVEIRA, Luis Gustavo Miranda de. Compliance e integridade: aspectos práticos e teóricos. Belo Horizonte: D'Placido, 2017.

QUIRINO, Israel. Compliance: uma nova prática no combate à corrupção nas empresas. Disponível em: <https://jus.com.br/artigos/58928/compliance-uma-nova-pratica-no-combatea-corrupcao-nas-empresas/1>. Acesso em: 03 setembro 2018.

SEN, Amartya. Sobre ética e economia. Tradução de Laura Teixeira Motta. São Paulo: Companhia das Letras, 1999. 